\title{
Perbandingan Fungsi Extremitas Atas pada Fraktur Metafise Distal Radius Intraartikuler Usia Muda Antara Tindakan Operatif Dan Non Operatif dengan Penilaian Klinis Quickdash Score
}

\author{
Edi Burhan ${ }^{1}$, Menker Manjas ${ }^{1}$, Ardian Riza $^{1}$, Erkadius $^{2}$
}

\begin{abstract}
Abstrak
Fraktur metafise distal radius merupakan fraktur dengan insiden tertinggi kedua pada usia tua di luar fraktur daerah panggul. Di Rumah Sakit Dr. M. Djamil Padang terdapat 122 dari 612 kasus fraktur radius, antara Januari 2011 - Juni 2012. Tujuan utama terapi ini adalah pengembalian permukaan sendi ke posisi anatomis dengan fiksasi yang stabil dan pengembalian fungsi extremitas atas semaksimal mungkin. Metode: Penelitian ini berupa penelitian retrospektif yang dilakukan di poliklinik orthopaedi RSUP Dr M Djamil Padang pada bulan November-Desember 2012 pada pasien fraktur metafise distal radius intraartikuler usia muda yang mendapat tindakan operatif dibandingkan dengan kelompok non-operatif dengan penilaian klinis Quick DASH Score. Sampel yang digunakan sebanyak 30 orang dari 55 orang yang memenuhi kriteria inklusi. Hasil: Ada hubungan yang bermakna antara fungsi extremitas atas dengan penilaian Quick DASH Score antara tindakan operatif pada fraktur distal radius intraartikuler usia muda dengan tindakan non-operatif ( $p$ Fisher $=0,010$ ). Tidak terdapat hubungan bermakna antara Quick DASH Score dengan jenis kelamin dan diagnosa kanan atau kiri. Pembahasan: Terdapat perbedaan yang bermakna antara pasien fraktur metafise distal radius intraartikuler pada usia muda yang mendapat tindakan operatif berupa ORIF dengan yang mendapatkan tindakan non-operatif berupa pemasangan Gips.
\end{abstract}

Kata kunci: Fraktur Metafise Distal Radius, Tindakan Operatif dan Non Operatif, Quick Dash Score

\begin{abstract}
Fracture metafise distal radius is fracture with second highest incident on old age besides a fracture in the pelvic area. In the Dr. M. Djamil Hospital found 122 from 612 cases fracture of radius from january 2011 to june 2012. The main purpose therapy is restore the joint in the surface position anatomically by fixation a stable and restore the function upper extremitas over their best. Method: This study is a retrospective conducted at the Orthopaedi clinic of Dr M Djamil Hospital in November-December 2012 on young age patinet with the distal radius metafise intrartikular fracture who got the operative treatment in compare with non-operative groups with clinical assessment Quick Dash Score. The sample used is 30 people from 55 people who meet criteria for inclusion. Result: There is meaningful relationship the function upper extremitas with Quick Dash Score a distal radius fracture actions on intraartikuler at a young age that got an operative treatment and non-operative ( $p$ Fisher $=0,010$ S). There is not meaningful relationships between Quick Dash Score with gender and diagnosis right or left. Discussion: There is significant difference between patients of intraarticuler radius distal metafise fractur who get operatif treatment, such as ORIF and the pasients who get non-operatif treatment, such as Gips.
\end{abstract}

Keywords: Metafise Distal Radius Fracture, Operatif and Non Operatif Treatment, Quick Dash Score

Affiliasi penulis : 1. Bagian Bedah Fakultas Kedokteran Universitas Andalas, 2. Bagian Fisiologi Fakultas Kedokteran Unand,

Korespondensi : Edi Burhan, email : onkologibedah@gmail.com, Telp/Hp : 081363140244

\section{PENDAHULUAN}

Fraktur metafise distal radius merupakan fraktur dengan insiden tertinggi kedua pada usia tua selain fraktur pada daerah panggul. Di negara Swedia angka kejadian pada fraktur metafise distal radius adalah 24 per 10.000 orang/tahun. Rasio antara perempuan : laki-laki dari tingkat kejadian pada pasien fraktur metafise distal radius adalah 3:1. Insiden meningkat sebanding dengan meningkatnya usia pada laki-laki dan perempuan. Kejadian pada pasien fraktur metafise distal radius di bawah usia 50 tahun (usia muda 16 sampai 50 tahun) sekitar 9 per 10.000 orang/tahun tanpa memandang jenis kelamin. Pada pasien wanita insiden meningkat tajam dari usia diatas 50 tahun dan hampir dua kali lipat dengan setiap interval usia 10 tahun sampai usia 70 tahun dan mencapai puncaknya setelah usia 90 tahun untuk 144 per 10.000 orang/tahun. Di Rumah sakit Dr. M. Djamil Padang dijumpai kasus fraktur metafise distal radius sebanyak 122 kasus dari 612 kasus fraktur radius, dari rentang waktu Januari 2011 - Juni 2012.

Pada pasien usia tua fraktur metafise distal radius penyebab tersering adalah low energy trauma, dan lebih banyak ditemukan pada wanita. Pada pasien usia muda fraktur metafise distal radius penyebab tersering di sebabkan high energy trauma baik pada laki-laki dan perempuan. Pada pasien wanita tua selain masalah pada frakturnya, sering didapatkan masalah lain yaitu kualitas tulang yang menurun. Hal ini menjadi tantangan untuk dapat menentukan metode penatalaksanaan yang tepat. Pada pasien usia muda dengan kualitas tulang yang masih bagus pada fraktur metafise distal radius dengan penatalaksanaan yang tepat didapatkan hasil fungsi extremitas atas pasca tindakan yang memuaskan. 
Pada pasien usia tua tidak mempermasalahkan adanya gangguan pada fungsi extremitas atas dan adanya deformitas pasca tindakan, namun pada pasien usia muda dengan meningkatnya kejadian pada fraktur metafise distal radius dengan tingginya aktifitas dan produktifitas di usia muda yang menggunakan tangan maka di butuhkan metoda tindakan yang paling tepat untuk dapat menjamin hasil fungsi extremitas atas yang maksimal.

Penatalaksanaan pada pasien fraktur metafise distal radius telah berubah dari waktu ke waktu. Dahulu closed reduction dan immobilisasi dengan gips sirkuler merupakan pilihan utama. Saat ini pilihan terapi pada pasien fraktur metafise distal radius semakin beragam. Penatalaksanaan pada pasien fraktur metafise distal radius sangat mempengaruhi fungsi extremitas atas pada saat pemulihan. Maka pilihan yang tepat pada jenis tindakan akan mempengaruhi fungsi extremitas atas. Pemilihan jenis tindakan yang tepat dari tenaga medis sangat mempengaruhi fungsi extremitas atas, apalagi kalau pada pasien fraktur metafise distal radius intraartikuler. Tujuan utama terapi pada pasien fraktur metafise distal radius intraartikuler adalah mengembalikan permukaan sendi pada posisi anatomis dengan fiksasi yang stabil dan mengembalikan fungsi extremitas atas semaksimal mungkin. Namun tenaga medis dan fasilitas yang ada sangat mempengaruhi hasil tindakan demikian, karena itu peneliti akan membandingkan hasil fungsi extremitas atas pada pasien fraktur metafise distal radius intraartikuler usia muda menggunakan tindakan operatif dengan non operatif dengan penilaian klinis Quick DASH Score di Bagian Bedah Ortopedi RSUP Dr. M. Djamil Padang.

Sampai saat ini ada berberapa metode skor yang telah dipublikasi untuk penilaian klinis pada fungsi extremitas atas yaitu ASES (American Shoulder and Elbow Surgeons Standardized Shoulder Assesment form), UCLA (University of California Los Angeles Shoulder rating Scale), The Oxford Shoulder Questionnare, The Imatani shoulder Score, SF36. Alat ukur yang diisi oleh pasien contohnya $D A S H$ (Disability of the Arm Shoulder and Hand Questionnaire) dan Oxford Shoulder Questionnare. ASES adalah ukur yang diisi oleh klinisi dan pasien.

$D A S H$ adalah alat pengukuran klinis yang responsif, valid dan terpercaya untuk menilai ekstremitas atas. Kuesioner ini terdiri dari 30 buah pertanyaan yang di isi sendiri oleh pasien. Pertanyaan kuesioner diklarifikasikan menjadi fungsi fisik, fungsi sosial, rasa nyeri dan gangguan tidur. Nilai rentang DASH adalah dari 0 (tidak normal) sampai 100 (normal)

DASH diperkenalkan oleh American Academy of Orthopaedic Surgeons berkerjasama dengan sejumlah organisasi dan di anggap baik untuk penilaian klinis pada sendi pergelangan tangan dan ekstremitas atas berdasarkan kepuasan pasien. $D A S H$ sudah di adopsi dalam berbagai bahasa antara lain Bahasa Jerman, Italia, Spanyol, Swedia, Prancis, Belanda dan Jepang dengan reliabilitas dan validitas yang sebanding dengan versi aslinya.

Quick DASH score adalah modifikasi dari DASH. Quick DASH Score berisi 11 pertanyaan sehingga lebih sederhana dan waktu pengisiannya lebih singkat. Nilai rentang Quick DASH Score sama dengan DASH, Yaitu 0 (tidak normal) sampai 100 (normal). Quick DASH Score memiliki presisi yang sama dengan $D A S H$ untuk menilai fungsi extremitas atas.

Bentuk asli Kuesioner Quick DASH Score adalah dalam bahasa inggris, Penilaian ini menggunakan kuesioner Quick DASH Score yang telah diterjemahkan kedalam bahasa Indonesia oleh Pusat Pelatihan Bahasa.

Dengan mengetahui hasil fungsi extremitas atas pada penatalaksanaan pada pasien fraktur metafise distal radius intraartikuler usia muda melalui penilaian klinis Quick DASH Score, dapat ditentukan metode tindakan yang tepat, diharapkan dapat mengurangi morbiditas dan komplikasi pasca trauma.

\section{METODE}

Rancangan penelitian berupa penelitian retrospektif. Hasil Quick DASH Score pada kelompok operatif di bandingkan dengan kelompok non-operatif pada pasien fraktur metafise distal radius intraartikuler usia muda.

Penelitian dilakukan di RSUP Dr. M. Djamil pada pasien fraktur metafise distal radius intraartikuler usia muda yang dilakukan tindakan operatif dan non operatif periode Januari 2011 - Juni 2012. Wawancara dilakukan di poliklinik orthopedi dan mendatangi ke rumah pasien bulan november dan desember 2012 .

Penelitian dilakukan pada penderita terhadap pasien usia muda yang berumur 16 sampai 50 tahun dengan fraktur metafise distal radius intraartikuler yang dilakukan tindakan operatif dengan non-operatif. Besar sampel ditentukan menurut perhitungan berdasarkan proporsi. Jadi jumlah sampel yang akan di ambil adalah : 30 sampel.

\section{HASIL}

Dari data rekam medis yang di dapat kurun waktu januari 2011 sampai dengan juni 2012 terdapat 612 kasus fraktur yang mengenai tulang radius dijumpai 122 kasus diantaranya fraktur ujung distal radius intra dan extraartikuler dari segala usia yang mendapatkan pengobatan dan didiagnosa di instalasi gawat darurat dan poli ortopedi di RSUP Dr. M Djamil Padang. Jumlah pasien yang fraktur metafise distal radius intraartikuler usia muda menggunakan tindakan operatif dan non operatif di Bagian Bedah Ortopedi RSUP Dr. M. Djamil Padang yang memenuhi kriteria inklusi adalah 55 orang. Diantara 55 orang yang memenuhi kriteria inklusi terdiri dari 30 pasien yang mendapat tindakan operatif dan 25 orang yang mendapat tindakan non operatif

Setelah dilakukan seleksi berdasarkan kriteria inklusi didapatkan yang memenuhi didapat yang memenuhi syarat ada 55 pasien. Peneliti hanya melakukan penelitian pada 30 pasien yang di ambil secara acak dari tindakan operatif 15 pasien dan non operatif pada 15 pasien. Dilakukan pengambilan data penilaian klinis Quick DASH Score pada 30 pasien di atas dengan mengisi kuisioner di poli ortopedi poli ortopedi di RSUP Dr. M. Djamil Padang dan mendatangi pasien ke rumah pasien. Dari 30 pasien yang di teliti terdiri atas 18 pasien laki-laki dan 12 pasien perempuan. Dari 15 pasien yang mendapat tindakan operatif terdiri atas 9 pasien laki-laki dan 6 pasien perempuan dan 15 pasien yang mendapat tindakan non operatif terdiri atas 9 pasien laki-laki dan 6 pasien perempuan.

Terdapat berberapa kendala dalam pengambilan data di rekam medis, diantaranya terdapat keterangan alamat yang tidak jelas, diagnosa yang tidak lengkap di cantumkan pada status, dan berberapa pasien yang 
jenis tindakan operasi yang tak dijelaskan karena laporan operasi yang tidak jelas atau laporan operasi yang tidak dijumpai. Di jumpai berberapa kendala pada pengambilan data kuisioner diantara 30 pasien yang diambil data kuisioner sekitar 20 pasien yang mempunyai hasil radologis yang sebelum operasi. Diantara 20 hasil radiologis yang di nilai terdapat 8 pasien fraktur metafise distal radius tipe VII, 5 pasien fraktur metafise distal radius tipe IV, 5 pasien fraktur metafise distal radius tipe III dan 2 pasien fraktur metafise distal radius tipe $\mathrm{V}$. Diantara 20 hasil radiologis yang di dapat 12 pasien yang mendapat tindakan operatif dan 8 pasien yang mendapat tindakan non operatif.

Waktu dilakukan Waktu pasca tindakan yang di ambil diatas 6 bulan catatan terakhir tindakan bulan mei 2012, sedangkan penelitian dilakukan bulan november dan desember 2012.

Tabel. 1 Karakteristik pasien metafise distal radius intraartikuler yang di teliti di RSUP dr. M Djamil dari januari 2011 sampai juni 2012

Tabel 1.1 Umur pasien metafise distal radius intraartikuler

\begin{tabular}{llll}
\hline \multirow{2}{*}{ Umur } & \multicolumn{2}{c}{ Tindakan } & \\
\cline { 2 - 3 } & $\begin{array}{l}\text { Non } \\
\text { operasi }\end{array}$ & Operasi & Total \\
& \multicolumn{2}{c}{ Op } & \\
\hline $20-29$ & 3 & 7 & 12 \\
$30-39$ & 1 & 6 & 9 \\
$40-49$ & 6 & 1 & 2 \\
\hline Grand & 15 & 15 & 7 \\
\hline Total & 15 & 30 \\
\hline
\end{tabular}

Dari tabel diatas dapat dilihat bahwa kasus terbanyak ditemukan pada rentang usia dibawah 20 tahun dan kasus paling sedikit ditemukan pada rentang usia 30-39 tahun. Subjek dengan non operatif memiliki usia rata-rata $31 \pm 12,4$ tahun, dan subjek operatif memiliki usia rata-rata $23,1 \pm 7,4$ tahun $(\mathrm{t}=$ $2,131 ; p=0,021)$.

Tabel 1.2 Jenis kelamin metafise distal radius intraartikuler

\begin{tabular}{cccc}
\hline \multirow{2}{*}{$\begin{array}{c}\text { Jenis } \\
\text { kelamin }\end{array}$} & \multicolumn{2}{c}{ Tindakan } & \multirow{2}{*}{ Total } \\
\cline { 2 - 3 } & Non operasi & Operasi & \\
\hline Laki-laki & 9 & 9 & 18 \\
Perempuan & 6 & 6 & 12 \\
\hline Grand & 15 & 15 & 30 \\
Total & 15 &
\end{tabular}

Chi-square $=0,000 \mathrm{NS}$

Dari tabel diatas dapat dilihat bahwa kasus pada jenis kelamin laki-laki lebih banyak (18 pasien) jika dibandingkan dengan jenis kelamin perempuan (12 pasien) dengan jumlah yang sama untuk setiap tindakan Operatif dan Non Operatif.
Tabel 1.3 Diagnosa kanan atau kirì

\begin{tabular}{lccc}
\hline \multirow{2}{*}{$\begin{array}{c}\text { Jenis } \\
\text { kelamin }\end{array}$} & \multicolumn{2}{c}{ Diagnosa } & \\
\cline { 2 - 3 } & $\begin{array}{l}\text { \# metafise } \\
\text { distal } \\
\text { radius (D) }\end{array}$ & $\begin{array}{l}\text { \# metafise } \\
\text { distal } \\
\text { radius (S) }\end{array}$ & \\
\hline Laki-laki & 10 & 8 & 18 \\
Perempuan & 5 & 7 & 12 \\
\hline Total & 15 & 15 & 30 \\
\hline
\end{tabular}

Chi-square $=0,556 \mathrm{NS}$

Dari tabel diatas dapat dilihat bahwa kasus lebih banyak terjadi pada jenis kelamin laki-laki (18 pasien) dengan 10 pasien untuk fraktur metafise distal radius kanan dan 8 pasien untuk fraktur metafise distal radius kiri, dibandingkan dengan jenis kelamin perempuan (12 pasien) dimana 5 pasien untuk fraktur metafise distal radius kanan dan 7 pasien untuk fraktur metafise distal radius kiri.

Tabel 1.4 Waktu pasca tindakan metafise distal radius intraartikuler

\begin{tabular}{lccc}
\hline \multirow{2}{*}{$\begin{array}{c}\text { Jenis } \\
\text { kelamin }\end{array}$} & \multicolumn{2}{c}{ Diagnosa } & \multirow{2}{*}{ Total } \\
\cline { 2 - 3 } & $\begin{array}{l}\text { \# metafise } \\
\text { distal } \\
\text { radius (D) }\end{array}$ & $\begin{array}{l}\text { \#metafise } \\
\text { distal } \\
\text { radius (S) }\end{array}$ & \\
\hline Laki-laki & 10 & 7 & 18 \\
Perempuan & 5 & 8 & 12 \\
\hline Total & 15 & 15 & 30 \\
\hline
\end{tabular}

Chi-square $=1,250 \mathrm{NS}$

Dari tabel di atas dapat di lihat bahwa dari 30 pasien yang di jadikan sampel penelitian waktu pasca tindakan yang di periksa $6-12$ bulan sebanyak 18 pasien dan di atas 12 bulan sebanyak 12 pasien.

Tabel 2. Hubungan antara Quick DASH Score dengan tindakan pasien fraktur metafise distal radius intraartikuler yang di teliti di RSUP dr. M Djamil dari januari 2011 sampai juni 2012

\begin{tabular}{|c|l|l|l|}
\hline \multirow{2}{*}{ qDASH } & \multicolumn{2}{|c|}{ Tindakan } & \multirow{2}{*}{ Total } \\
\cline { 2 - 3 } & Gips & ORIF & \\
\hline 56.8 & 2 & & 2 \\
\hline 59.1 & 2 & & 2 \\
\hline 61.4 & 1 & & 1 \\
\hline 65.9 & 2 & & 2 \\
\hline 68.2 & 2 & & 2 \\
\hline 79.5 & & 2 & 2 \\
\hline 84.1 & 5 & 1 & 6 \\
\hline 88.6 & & 1 & 1 \\
\hline 90.9 & 1 & & 1 \\
\hline 97.7 & & 2 & 2 \\
\hline 100.0 & & 9 & 9 \\
\hline Total & 15 & 15 & 30 \\
\hline & & & \\
\hline
\end{tabular}


Pada table di atas terdapat hasil Quick DASH Score di hubungkan dengan tindakan dari data yang diambil dari 30 pasien yang dilakukan wawancara.

Tabel 3. Hasil Quick DASH score pasien fraktur metafise distal radius

\begin{tabular}{|c|c|c|c|}
\hline \multirow{2}{*}{ qDASH } & \multicolumn{2}{|c|}{ Tindakan } & \multirow{2}{*}{ Total } \\
\hline & $\begin{array}{l}\text { Non } \\
\text { operatif }\end{array}$ & Operatif & \\
\hline$<80$ & 9 & 2 & 11 \\
\hline $80 />$ & 6 & 13 & 19 \\
\hline Total & 15 & 15 & 30 \\
\hline
\end{tabular}

Dari hasil tabel diatas dapat di simpulkan bahwa terdapat hubungan yang bermakna antara Quick DASH Score dengan Tindakan. Diatas dapat diambil kesimpulan bahwa tindakan operatif lebih memberikan hasil fungsi tangan lebih baik dari non operatif.

\section{Pembahasan}

Dari penelitian yang dilakukan dapat ditemukan bahwa terdapat perbedaan yang bermakna antara pasien fraktur metafise distal radius intraartikuler pada usia muda yang mendapat tindakan operatif berupa ORIF dengan yang mendapatkan tindakan non-operatif berupa pemasangan Gips. Dari 12 poin pertanyaan yang diajukan kepada responden dan terlihat bahwa pada pertanyaan $1,2,4,5$ dan 7 responden yang mendapat tindakan non operatif menyatakan adanya keluhan ringan/sedang saat melakukan aktifitas sebagaimana yang ditanyakan.

Terdapat berberapa kendala waktu pengambilan data di rekam medis diantaranya terdapat keterangan alamat yang tidak jelas, diagnosa yang tidak lengkap di cantumkan pada status, dan berberapa pasien yang jenis tindakan operasi yang tak dijelaskan karena laporan operasi yang tidak jelas atau laporan operasi yang tidak dijumpai. Kesulitan ditemui dalam mendapatkan alamat penderita karena sering tidak lengkapnya identitas yang tertulis di dalam rekam medik rumah sakit. Dalam menyusuri alamat sebagian penderita, dilakukan juga kontak dengan keluarga yang berdomisili di Sumatera Barat, yang biasanya alamat keluarga penderita tersebut tercantum di lembar persetujuan atau penolakan tindakan. Dari data rekam medis yang di dapat juga terdapat ketidaklengkapan dari diagnosa dari fraktur metafise distal radius intraartikuler berdasarkan tipe fraktur metafise distal radius. Dalam penelitian ini terpaksa peneliti menegakkan diagnose fraktur metafise distal radius intraartikuler setelah melihat rontgen foto pasien pada saat wawancara di poli atau dirumah pasien. Dari data rekam medis juga didapati ketidak jelasan tindakan operasi karena laporan operasi yang kurang menjelaskan tentang jenis tindakan, laporan operasi yang tidak dijumpai didalam data rekam medis.

Di jumpai berberapa kendala pada pengambilan data kuisioner diantara 30 pasien yang diambil data kuisioner sekitar 20 pasien yang mempunyai hasil radiologis yang sebelum operasi. Diantara 20 hasil radiologis yang di nilai terdapat 8 pasien fraktur metafise distal radius tipe VII, 5 pasien fraktur metafise distal radius tipe IV, 5 pasien fraktur metafise distal radius tipe III dan 2 pasien fraktur metafise distal radius tipe V. Diantara 20 hasil radiologis yang di dapat 12 pasien yang mendapat tindakan operatif dan 8 pasien yang mendapat tindakan non operatif.

\section{KESIMPULAN}

1. Tindakan operatif memberikan hasil yang lebih baik untuk fungsi extremitas atas daripada non operatif terhadap pasien fraktur metafise distal radius intra artikuler usia muda dinilai dari Quick DASH Score.

2. Tindakan operatif merupakan metode tindakan yang dapat mengurangi morbiditas dan komplikasi pasca trauma.

\section{Saran}

Diharapkan pada penanganan fraktur metafise distal radius intraartikuler usia muda lebih memperhatikan kelengkapan data di rekam medis seperti alamat, diagnosa, tindakan dan laporan tindakan. Disamping itu juga perlu peningkatan kualitas pelayanan, penanganan dan peralatan di rumah sakit hingga dapat memberikan hasil dan fungsi extremitas atas lebih baik pada pasien usia produktif.

\section{DAFTAR PUSTAKA}

1. Robert A.E. Calyton, Mark S, Gaston, Stuart H. Ralston, Charles M.Court-Brown and Margarett M McQueen, 2009. Association Between Decreased Bone Mineral Density and Severity of Distal Radial Fracture, J Bone Joint Surg Am.,91:613-619.doi: 10.2106/JBJS.H.00408.

2. Kenneth J.Koval, John J. Harrast, Jeffrey $O$. Anglen and James N. Weinstein, 2008. Fracture of The Distal Part of the Radius. The Evolution of Practice Over Time. Where's the Evidence?, J Bone Joint Surg Am., 90: 1855-1861.

3. Richard A. Rogachefsky, Scott R. Lipson Brooks Applegate, Elizabeth Anne Oullette, Arnold M. Savenor and John A. McAullife, 2001. Treatment of Severely Comminuted Intra-Articular Fractures of the Distal And of the Radius by Open Reduction and Combined Internal and Exterternal Fixation, J Bone Joint Surg Am, 83:509.

4. Bagian Rekam Medis RSUP M. Djamil Padang, 2012.

5. Paul M. Simic and Andrew J. Weiland, 2003. Fractures of Distal Aspect of the Radius: Changes in treatment Over The Past Decades, J Bone joint Surg Am, 85:552-564.

6. Tamara D. Rozental, Eric C. Makhni, Charles S. Day and Mary L. Bouxsein, 2008, Improving Evaluation and Treatment For Osteoporosis Following Distal Radial Fractures. A Prospective Randomized Intervention. J Bone Joint Surg Am., 90:953-961.

7. Michael Bottlang, Josef Doornink, Gregory D. Byrd, Daniel C. Fitzpatrick and Steven M. Madey, 2009. A Nonlocking End Screw Can Decrease Fracture Risk Caused by Locked Plating in the Osteoporotic Diaphysis, J Bone JointSurg Am, 91: 620-627.

8. J.L Marsh, J. Buckwalter, R. Gelberman, D. Dirschl, S.Olson, T. Brown and A.Llinias, 2002. Articular Fractures: Does an Anatomic Reduction Really Change the Result? J Bone Joint Surg AM, 84:1259-1271

9. Tamara D.Rozental, Pedro K. Beredjiklian and David J. Bozentka, 2003. Functional Outcome and Complication Following Two Types of Dorsal 
Plating for Unstable Fractures of the Distal Part of the Radius, J Bone Joint Surg AM., 85:1956-1960.

10. Robert W Bucholz, James D Heckman, 2001. Rockwood And Green's Fractures in Adults, Lippincott Williams and Willkins.

11. . P.C. Strohm, C.A. Muller, T. Boll and U Pfister, 2004. T Boll and U. Pfister, 2004. Two Procedures for kirshner Wire Osteosynthesis of Distal Radial Fractures. A Randomized Trial, J Bone Joint Surg Am., 86:2621-2628.

12. Rory D Macnair, Cristopher J. Ingham and Benjamin J. Davis, 2008. Comparison of External and Percutaneous Pin Fixation for Intra-articular Distal Radial Fractures, J Bone Joint Surg Am. 90: 1784.

13. Frankie leung, Yuan-kun tu, Winston Y.C. Chew and Shew-ping Chow, 2008. Comparison of External and Percutaneusor Pin Fixation with Plate Fixation for Intra-articular Distal Radial Fractures. A Randomized Study, J Bone Joint Surg Am., 90: 16-22.

14. R Grewall; B Perey, 2005. A Randomized Prospective Study on Treatment of Intra-articular Distal Radius Fracture: Open Reduction and Internal Fixation with Dorsal Plating versus Mini Open Reduction, Percutaneous Fixation and External Fixation, The Journal of Hand Surgery; 30A, 4; ProQuest Medical Library pg 764.

15. Zvi Margaliot, Steven C Haase, 2005. A Meta Analysis of Outcome of External Fixation versus Plate Osteosynthesis for Unstable Distal Radius Fracture, The Journal of Hand Surgery; 30A,6;ProQuest Medical Library pg 1185.

16. Kevin C. Chung and Elizabeth A. Petruska, 2007. Treatment of Unstable Distal Radial Fractures with the Volar Locking Surgical Technique Plating System, J Bone Joint Surg Am., 89:256-266.

17. David Ring, Karl Prange of Motion mersberger and Jesse B. Jupiter, 2005. Combined Dorsal and Volar Plate Fixation of Complex Fractures of the Distal Part of the Radius, J Bone Joint Surg Am, 87: 195-212.

18. Jesse B.Jupiter, M, Marent-Huber and the LCP Study Group, 2009. Operative Management of Distal Radial Fractures with 2.4-Milimeter Locking Plates. A Multicenter Prospective Case series, J Bone Joint Surg Am., 91:55-65.

19. Kevin C. Chung, Andrew J. Watt, Sandra V. Kotsis, Zvi Margaliot, Steven C. Haase and H. Myra Kim, 2006. Treatment of Unstable Distal Radial Fractures with the Volar Locking Surgical Technique Plating System, J Bone Joint Surg Am., 88:2687-2694.

20. David R. Ruch, T. Adam Ginn, Charles C. Yang, Beth P. Smith, Julia Rushing and Douglas P Hanel, 2005. Use of Distraction Plate for Distal Radial Fractures with Metaphyseal and Diaphysel comminution, J Bone Joint Surg Am., 87: 945-954.
21. David Ring, 2009. Volar Locked Plating Improved wrist Range of Movement More Than External Fixation for Distal Radial Fracture, J Bone Joint Surg Am., 91:1280.

22. Rodriguez-Merchan EC. Plaster Cast versus Percutaneous pin Fixation for Cominuted Fractures of the Distal Radius in Patients Between 46 and 65 years of age. J Orthop Trauma. 1997;11:212-7.

23. Louis Solomon, D Warwick S Nayagam Injuries of the forearm and Wrist in Apley's Sistem of Orthopeadic and Fractures 8th ed; Arnold; $2001 ; 611-628$.

24. Robert Bruce Salter; Text book of Disolders injuries of the Musculoskeletal 3rd ed; William and Wilkins; 1999;570-573.

25. JK Bradway, PC Amadio, and WP Cooney Open Reduction and Internal Fixation of Displaced, Comminuted Intra-articuler Fractures of the Distal and of the Radius, J Bone Joint Surg Am; Jul 1987;71:839-847.

26. Joint J Gartland, JR. and Charles W. Werley. Evaluation of Healed colles Fractures. J Bone Joint Surg Am., Oct 1951;33: 895-907

27. Gummesson C, Atroshi I, Ekdahl C. The Disability of the Arm, Shoulder and hand (DASH) Hasil akhir questionnaires: Longitudinal Construct Validity and measuring self-rated health change self-rated heath change after surgery, BMC Musculoskelet

28. S Terry Canale, 2005. Campbell"s Operative Orthopaedic, 11th ed. Mosby Elsvier.

29. Thomas P Ruedi, William M Murphy, 2000. AO Principles of Fracture Management, Thieme, Stuttgart-New York.

30. Neil G. Harness, David Ring, David Zurakowski, Gordon J.Harris and jesse B. Jupiter, The Influence of three-Dimensional Computed Tomography Radial Reconstruction on The Characterization and Treatment of Distal Fractures, J Bone Joint Surg AM., 88:1315-1323.

31. S. A. Earnshaw, A. Aladin, S. Surendran and C. G. Moran, 2002. Closed Reduction of Colles Fractures: Comparison of Manual Manipulation and Finger-Trap Traction: A Prospective, Randomized Study, J Bone Joint Surg Am., 84:354-358.

32. Scott Ellis and Andrew j. Weiland, 2006. Indirect reduktion and Percutaneus Fixation Led to a Rapid Recovery and Better Function Than Open Reduction for Intra-articular fractures of the Distal End of the Radius, J Bone Joint Surg Am, 88:455.

33. R Magetsari, 2009. Luaran Fungsi Sendi Pergelangan Tangan pada Fraktur Distal radius Sesudah Tindakan Fiksasi Percutaneus Pinning Dibandingkan dengan Tindakan Long Arm Cast. Artikel penelitian. Berkala Kesehatan Klini, Vol XV, No.1: 42-48.

34. A. Satar et al.2012. Can functional outcome in patients with distal radius fracture be affected by radiological deformities. Original Article. Pak $J$ Surgery. 